Doi: HTTPS://DOI.ORG/10.23910/IJBSM/2018.9.2.1859

\title{
Interdisciplinary Approach for Sustainable Forest Management
}

\author{
Natalya Sergeevna Ivanova
}

Botanical Garden of the Ural Branch of the Russian Academy of Sciences, Yekaterinburg, Russia 202a, $8^{\text {th }}$ March Street, Yekaterinburg (620 144), Russia

\section{Corresponding Author}

Natalya Sergeevna Ivanova

e-mail: i.n.s@bk.ru

\author{
Article History \\ Article ID: AR1859 \\ Received in $26^{\text {th }}$ January, 2018 \\ Received in revised form $19^{\text {th }}$ February, 2018 \\ Accepted in final form 25 $5^{\text {th }}$ March, 2018
}

\begin{abstract}
The possibilities of the Catastrophe Theory for predicting the dynamics of forest ecosystems and developing scenarios for sustainable forest management are discussed. The main features of the approach are described. The achievements and difficulties of application for the Catastrophe Theory in scientific research have been discussed. Examples are given of the application for the study of ecotones (steppe - forest), succession modeling, forest restoration prediction and forest description as a multilayer system. Particular attention is paid to the problem of reforestation. The Catastrophe Theory can provide an explanation for the appearance of abrupt changes in reforestation as a result of minor changes in controlling factors and why such changes occur in different configurations of control factors. Methods of Catastrophe Theory allow, identifying and predicting crises in the forest development, which is very important for the management of bioresources. A great achievement of modern Catastrophe Theory is the transition from qualitative forecasting of generalized situations to quantitative prediction of real situations. Modern models, built on its basis and parameterized using field observations, describe real situations quantitatively. These models can be used to assess whether the trajectory is following the desired path and to estimate recovery rate or to forecasting possible scenarios. The methods of Catastrophe Theory are universal and can be used for all forests of the world and other ecosystems.
\end{abstract}

Keywords: Forest management, forecasting, catastrophe theory

\section{Introduction}

In connection with the understanding of the role of forests to maintain the stability of the biosphere and climate, the problem of sustainable forest management is acute (Messier et al., 2013; Beech et al., 2017). But, both the modelling results as good as the country predictions suggest that, at the global level, forest resource loss is likely to continue but slow down by 2030 (d'Annunzio et al., 2015). This tendency is due to the huge scale of timber harvesting and fires, so the problem of reforestation and conservation of forest resources is becoming more urgent (Maiti et al., 2016; Keane et al., 2017).

Despite of the many publications on this issue, there is still no comprehensive understanding of the mechanisms for changing forest ecosystems (Lankin, Ivanova, 2015). Also, the lack of quantitative methods for predicting the success of recovery is felt quite sharply (Benjamin et al., 2017). Gradually came the understanding that an interdisciplinary approach can help to solve this problem (Nadrowski et al., 2013; Gewin, 2014; Brown et al., 2014). In connection with it methods developed in other sciences (including mathematics) were started to use in the ecology. Multidisciplinary research between ecologists and statisticians has led to significant advances in many different aspects of biodiversity modeling (Warton, 2015; Clark et al., 2017; Warton and McGeoch, 2017). Some researchers were interested in the Catastrophe Theory. It is due to the fact that the methods of the Catastrophe Theory allow us to describe and predict crises in the development of ecosystems. There is no doubt that the timely identification of crisis situations in the process of reforestation is crucial for forest management (Lankin, Ivanova, 2015). However, the methods of Catastrophe Theory are used extremely rarely. First of all, this is due to insufficient awareness of modern researchers about new achievements in this direction.

\section{Basic Provisions}

The catastrophe theory can provide explanations for a number of phenomena, for instance, how abrupt changes in behavior can result from minute alterations in controlling factors, and why such changes occur at different control factor configurations depending on the past states of the system (Poston, Stewart, 1978; Grasman et al., 2009).

The beginnings of the catastrophe theory were laid in the 
classical works of Leonhard Euler. He worked on the theory of stability, which is a multifarious discipline studying patterns of behavior in different systems under the influence of external factors. The theory of stability of mechanical systems is most well-developed in the works of Euler. The Catastrophe Theory as a branch of mathematics began to take shape back in the mid-twentieth century. The creators of this theory are the French mathematician Rene Thom (Thom, Zeeman, 1975; Zeeman, 1976) and the Russian mathematician Arnold (1992).

This theory examines general principles, which manifest themselves in different situations, and helps to understand better the mechanism of natural forces in action. Catastrophes are intermittent changes that occur as a sudden response of a system to smooth changes in external conditions (Arnold, 1992). The value of an elementary catastrophe theory is that it reduces a great diversity of situations to a small number of standard schemes, which can be studied in detail.

Catastrophe theory cannot prevent a sudden deterioration of a situation; neither will it provide a quick resolution of the crisis. However, it allows you to delve deeper into the essence of the phenomena and processes of the real world and to understand the underlying mechanisms better. In mathematical terms, a catastrophe is a sudden restructuration of a system, a qualitative change ща its condition. It is of vital importance to be able to choose the right solution at the very start of a crisis. Henceforth, the catastrophe theory was popularized in the 1970s (Thom and Zeeman, 1975; Deakin, 1980; Gilmore, 1993), and was promoted as a strategy for modeling in various disciplines like physics, biology, psychology, and economics (Grasman et al., 2009). However, the models chosen were only qualitative. They described generalized situations and were of little use when solving specific practical tasks, and therefore, the transition to the quantitative level proved difficult and ultimately came to a standstill. It caused a great deal of criticism of the catastrophe theory (Deakin, 1978, 1980; Loehle, 1989; Rosser, 2007; Grasman et al., 2009), which almost out an end to further research.

Despite all this, stochastic formulations of the catastrophe theory have been found; statistical methods have been developed to allow a quantitative comparison of catastrophe models across the data available (Cobb, 1981; Cobb et al., 1983; Oliva et al., 1987; Wagenmakers et al., 2005; Grasman et al., 2009). However, a lack of software and special training necessary for biologists and foresters inhibited the use of the catastrophe theory for analyzing and forecasting the state of woody plants and their ecosystems. In recent years the situation has changed for the better. Grasman et al. (2009) proposed an add-on package for statistical computing environment $\mathrm{R}$, which implements the method of (Cobb et al., 1983), and extends it in a number of ways. In particular, the approach of Oliva et al. (1987) is adopted to allow for a behavioral variable that is embedded into multivariate response space. The package is available from the Comprehensive R Archive Network at http://CRAN.R-project. org/package=cusp.

\section{Examples of Models}

\subsection{Forest-steppe}

The model of the change from the forest to the steppe (and vice versa) presents a great interest for the analysis of vegetation dynamics in a changing climate. These models were studies by Armand and Kunasheva (1989), who conducted a research on the border between forest and steppe. They made a detailed analysis of critical states and described the change in vegetation in terms of the catastrophe theory. The upper wing of the cusp catastrophe is taken as forest ecosystems, with the lower wing corresponding to the steppe. The ecotone between the forest and the steppe has been analyzed as a hysteresis loop. The main focus of the work was to find the limiting (critical) values of the external and internal factors.

\subsection{Model of succession}

In most cases, forests consist of several woody species with different biological characteristics. Their share in the composition of the emerging forest does not remain constant and often varies dramatically (thereby showing discreteness), alongside smooth, continuous changes in factors. Frelich and Reich (1999) used the catastrophe theory to describe changes in woody species of boreal and tropical forests. Their model describes the dominance of woody species that are a characteristic of later succession stages. The authors put forward and tested a hypothesis about the role of neighborhood effects, which can be positive, negative and neutral. The second control variable in the system is disturbance severity. The model describes both sharp changes in states and the dynamics of succession.

The work by Isaev et al. $(2005,2008)$ is devoted to development of model describing succession in the forest communities as first and second order phase transitions. Changes in the species composition of wood communities caused by natural and anthropogenic factors are considered. The math model of sequential succession transition in the wood communities is proposed and verified. The model makes it possible to quantify the process of changing tree species in a single-aged forest stand, which is extremely common in taiga forests. It has been shown that the model is in good agreement with the actual data. The proposed approach allows establishing critical values of stand biomass at which the succession transition begins.

\subsection{Reforestation after timber harvesting}

We studied reforestation in the Ural Mountains (Russia) for more than 20 years (Ivanova, 1999, 2000, 2014; Ivanova, Zolotova, 2015, 2017). Quantitative data on the structure of indigenous forests, cuttings and secondary ecosystems of different ages were obtained. These data served as the basis for 


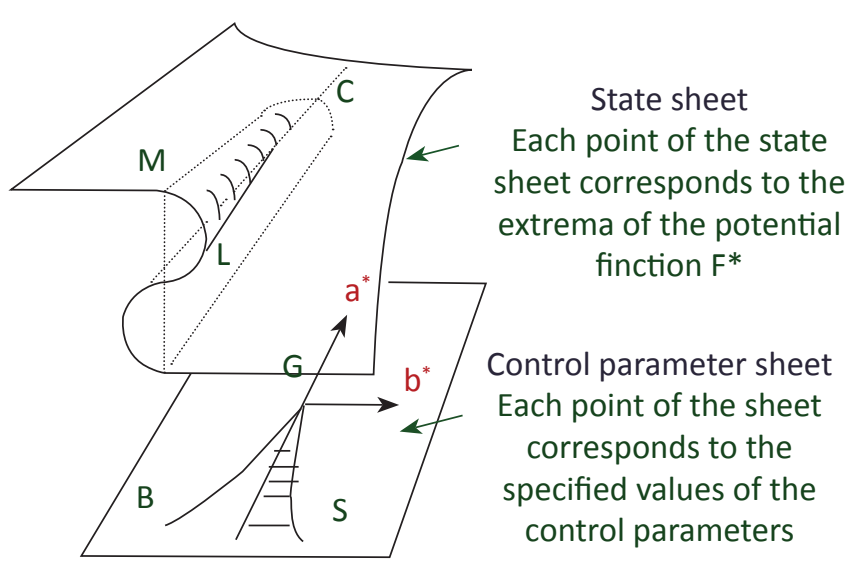

Figure 1: Model of the cusp catastrophe: $\mathrm{MCL}$ - metastable state, BGS - separatrix, $a^{*}, b^{*}$ - control parametrs

constructing mathematical models. The aim of the modeling was to forecasting of forest ecosystem dynamics as the basis for sustainable forest management. The cusp catastrophe was chosen as the basis for building models (Figure 1). The cusp catastrophe is one of the seven elementary catastrophes. In biological and behavioral sciences, the so-called cusp catastrophe model has been applied most frequently, as it is the simplest of the catastrophe models (Grasman et al., 2009). It is summed by the equation:

$\frac{d x}{d t}=\frac{\partial F}{\partial x}$ or $\frac{d x}{d t}=-(x 3+a x+b)$

Where, $\mathrm{F}$ is the potential function that determines the energy characteristics of the system.

$F(X, a, b)=\frac{1}{4} X^{4}+\frac{1}{2} a x^{2}+b$

In the process of constructing a generalized model for the formation of vegetation after harvest, Bystrai and Ivanova (2010) described the basic concepts and equations of Catastrophe Theory. They built a quantitative mathematical model that takes into account the peculiarities of the region and habitat for the dynamics of the vegetation of the Ural Mountains (Ivanova, Bystrai, 2010). This model allows you to make quantitative predictions of real situations. The existence of alternative lines of the succession dynamics of forests in the habitat was formalized within the framework of catastrophe theory. Quantitative methods for assessing the sustainability of reforestation were proposed (Bystrai, Ivanova, 2010; Ivanova et al., 2011; Ivanova, 2013; Ivanova, Zolotova, 2013). One of these methods is the construction of potential functions (Figure 2). Local and global stability of the forest ecosystem is determined by type of the potential functions (presence of minima and maxima). Minima show steady states. Special studies are devoted to the study of the effect of control parameters on the growth of woody plants (Ivanova et al., 2011). As a result, the critical thickness of the soil is determined, at which the equality of the numbers of pine and birch on felling is observed. It was 27 $\mathrm{cm}$ for the southern taiga forests of the Middle Urals. Natural

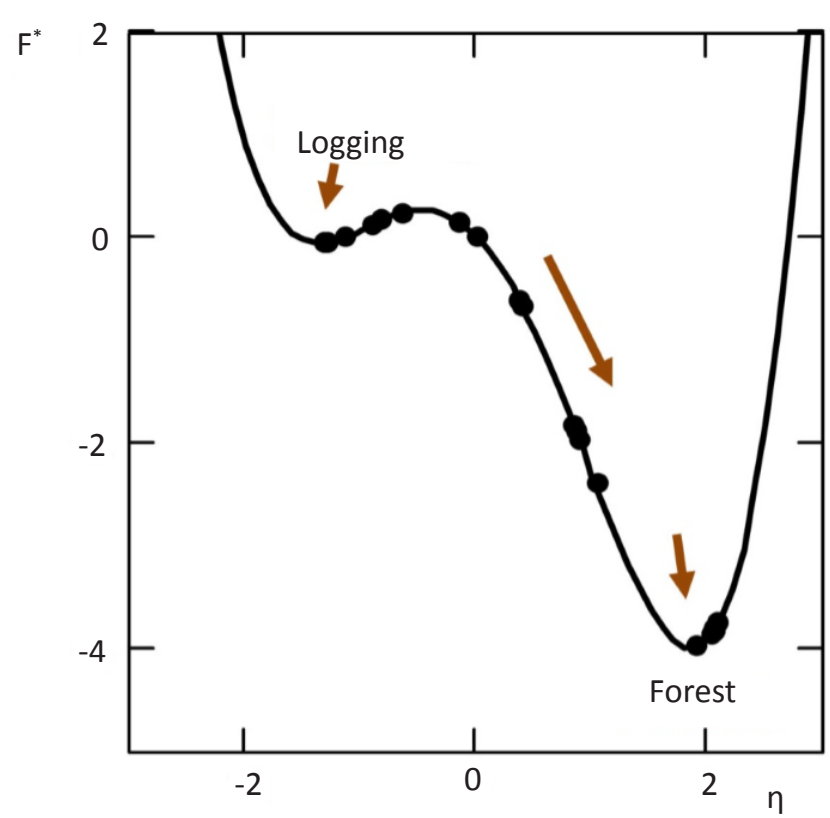

Figure 2: Potential function $\left(\mathrm{F}^{*}\right)$ of the cusp catastrophe: $\eta$ order parameter, the points correspond to natural ecosystems (loggings and forests that have different age and succession status)

regeneration of pine predominates on shallow soils. Natural regeneration of birch dominates on powerful soils. As a result, various forests are formed on different soils. Calculations show a satisfactory agreement of theory and experimental data. It reflects the perspectives of the catastrophe theory for describing, analyzing and forecasting forest ecosystems dynamics, sustainability assessment and crises identification.

\subsection{Model of a mosaic multi-tiered forest}

Guts, Hlyzov (2011) solve the problem of constructing a mathematical dynamic model of a mosaic multilevel forest, with the help of which it would be possible to predict the state of forests depending on the effect of various factors. Researchers proposed a mathematical model of a mosaic multi-tiered forest with a view to describing succession series (Guts, Hlyzov, 2011). The model is based on four controlling external factors that determine the ecosystem environment. Such factors were chosen: soil moisture, mosaic, the presence of competition and anthropogenic violations of forest ecosystems (deforestation, fires). The star catastrophe is the basis of the model. The star catastrophe describes seven equilibrium states simultaneously. However, only four states can be stable (Guts, Volodchenkova, 2012). This model is also used to describe the succession after harvesting and fires, the relationship between vegetation and soils, the degradation of birch forests under the influence of excessive moisture (Guts, Volodchenkova, 2012, 2015).

\section{Conclusion}

Thus, the Catastrophe Theory continues to be actively used to analyze the sustainability and restoration of forest ecosystems. 
Modern models, built on its basis and parameterized using field observations, describe real situations quantitatively. These models can be used to assess whether the trajectory is following the desired path and to estimate recovery rate or to forecasting possible scenarios. The methods of Catastrophe Theory are universal and can be used for all forests of the world and other ecosystems.

\section{Acknowledgement}

Author is acknowledges funding of research within the framework of the State task of the Botanical Garden of the Ural Branch of the Russian Academy of Sciences

\section{References}

Armand, A.D., Kunasheva, G.V., 1989. Transition of ecosystems through the critical state in area. In: Ecosystems are in a critical condition. Moscow: Nauka, 10-23

Arnold, V.I., 1992. Catastrophe Theory, (3rd eds.), Berlin, Springer-Verlag. 150 p. Doi:10.1007/978-3-642-58124-3.

Beech, E., Rivers, M., Oldfield, S., Smith, P.P., 2017. GlobalTreeSearch: The first complete global database of tree species and country distributions. Journal of Sustainable Forestry 36(5), 454-489.

Benjamin, C.S., Punongbayan, A.T., Dela Cruz, D.W., Villanueva, R.D., Baria, M.V.B., Yap, H.T., 2017. Use of Bayesian analysis with individual-based modeling to project outcomes of coral restoration. Restoration Ecology 25, 112-122. Doi:10.1111/rec.12395.

Brown, A.M., Warton, D.I., Andrew, N.R., Binns, M., Cassis, G., Gibb, H., 2014. The fourth-corner solution - using predictive models to understand how species traits interact with the environment. Methods in Ecology and Evolution 5, 344-352. Doi:10.1111/2041-210x.12163.

Bystrai, G.P., Ivanova, N.S., 2010. Approaches to the modelling of forest vegetation on the base of the theory of catastrophes. Agrarian bulletin of Ural (Agrarnyj vestnik Urala) 2, 75-79.

Clark, S.G., Palis, F., Trompf, G.W., Terway, T.M., Wallace, R.L., 2017. Interdisciplinary problem framing for sustainability: Challenges, a framework, case studies. Journal of Sustainable Forestry 36(5). Doi:10.1080/10 549811.2017.1330213.

Cobb, L., 1981. Parameter Estimation for the Cusp Catastrophe Model. Behavioral Science 26, 75-78.

Cobb, L., Koppstein, P., Chen, N., 1983. Estimation and moment recursion relations for multimodal distributions of the exponential family. Journal of the American Statistical Association, 78, 124-130.

d'Annunzio, R., Sandker, M., Finegold, Y., Min, Z., 2015. Projecting global forest area towards 2030. Forest Ecology and Management 352, 124-133. Doi:10.1016/j. foreco.2015.03.014.

Deakin, M., 1978. An elementary approach to catastrophe theory. Bulletin of Mathematical Biology 40, 429-450.
Deakin, M., 1980. Applied catastrophe theory in the social and biological sciences. Bulletin of Mathematical Biology 42, 647-679.

Frelich, L.E., Reich, P., 1999. Neighborhood effects, disturbance severity, and community stability. Ecosystems 2, 151166. Doi:10.1007/s100219900066.

Gewin, V., 2014. Interdisciplinary research: break out. Nature 511, 371-373. Doi:10.1038/nj7509-371a.

Gilmore, R., 1993. Catastrophe Theory for Scientists and Engineers. New York, Dover. 666.

Grasman, R., Van Der Maas, H., Wagenmakers, E-J., 2009. Fitting the Cusp Catastrophe in R: A cusp Package Primer. Journal of Statistical Software 32(8), 1-27. Doi:10.18637/ jss.v032.i08.

Guts, A.K., Hlyzov, E.O., 2011. Model of a forest ecosystem and succession modeling. Mathematical Structures and Modeling 23, 19-30.

Guts, A.K., Volodchenkova, L.A., 2015. Matematical model of interrelation "Vegetation-Soil" in forest ecosystems. Mathematical Structures and Modeling 3, 56-60.

Guts, A.K., Volodchenkova, L.A., 2012. Cybernetics of Forest Ecocystem Catastrophes. Omsk, KAN Publ. 220 p.

Isaev, A.S., Sukhovolsky, V.G., Buzykin, A.I., Ovchinnikova, T.M., 2008. Succession processes in forest communities: models of phase transitions. Coniferous boreal zones 25, 9-15.

Isaev, A.S., Sukhovolsky, V.G., Khlebopros, V.G., 2005. Simulation of the forest-forming process: phenomenological approach. Russian Journal of Forest Science (Lesovedenie) 1, 1-9.

Ivanova, N.S., 1999. Regeneration-age dynamics of the lower layers and vegetation classification principles in darkconiferous forests in the Southern Ural Mountains: dissertation of candidate of agriculture: 06.03.03, Natalya Sergeevna Ivanova, Yekaterinburg, 215.

Ivanova, N.S., 2000. Methods for the classification of mountain forests in the Southern Urals. Russian Journal of Forest Science (Lesovedenie), 4, 16-21.

Ivanova, N.S., 2013. Methods of the Estimation of Stability of Reforestation. International Journal of Applied and Fundamental Research 2. http://www.science-sd. com/455-24167.

Ivanova, N.S., 2014. Recovery of Tree Stand After Clearcutting in the Ural Mountains. International Journal of Bio-resource and Stress Management 5, 90-92. Doi:10 .5958/j.0976-4038.5.1.017.

Ivanova, N.S., Bystrai, G.P., 2010. Model of the formation of the tree layer structure on cuttings. Part 1. The control parameters. Agrarian bulletin of Ural (Agrarnyj vestnik Urala) 5, 85-89.

Ivanova, N.S., Zolotova, E.S., 2013. Model of forest restoration. Population Dynamics: Analysis, Modelling, Forecast 2, 50-60.

Ivanova, N.S., Zolotova, E.S., 2015. Ecological space of forest 
type in the montains of Middle Urals. Modern problems of education and science (Sovremenniye problemy nauki i obrazovanija) 3. Doi: 10.17513/spno.123-19372.

Ivanova, N.S., Zolotova, E.S., 2017. Impact of timber harvesting on vegetation in the Ural Mountains. International Journal of Bio-resource and Stress Management 8(1) 167-174. Doi: 10.23910/IJBSM/2017.8.1.1797.

Ivanova, N.S., Bystrai, G.P., Ohotnikov, S.A., Zolotova, E.S., 2011. Model of forests age-restoration in the Zauralsky hilly piedmont province. Modern problems of education and science (Sovremennye problemy nauki i obrazovaniya) 4. http://www.science-education. $\mathrm{ru} / 98-4754$.

Keane, R.E., Holsinger, L.M., Mahalovich, M.F., Tomback, D.F., 2017. Evaluating future success of whitebark pine ecosystem restoration under climate change using simulation modeling. Restoration Ecology 25, 220-233. doi:10.1111/rec.12419.

Lankin, Y.P., Ivanova, N.S., 2015. Methodological Problems in the Modeling of Ecosystems and Ways of Solutions. International Journal of Bio-resource and Stress Management 6, 631-638. Doi:10.5958/09764038.2015.00098.6.

Loehle, C., 1989. Catastrophe theory in ecology: a critical review and an example of the butterfly catastrophe. Ecological Modelling 49, 125-152. Doi: 10.1016/03043800(89)90047-1.

Maiti, R., Rodriguez, H.G., Ivanova, N.S., 2016. Autoecology and Ecophysiology of Woody Shrubs and Trees: Concepts and Applications. John Wiley \& Sons, 355.

Messier, C., Puettmann, K.J., David, K., 2013. Coates Managing Forests as Complex Adaptive Systems. Taylor \& Francis Group. Doi: 10.4324/9780203122808.

Nadrowski, K., Ratcliffe, S., Bonisch, G., Bruelheide, H., Kattge,
J., Liu, X., Maicher, L., Mi, X., Prilop, M., Seifarth, D., Welter, K., Windisch, S., Wirth, C., 2013. Harmonizing, annotating and sharing data in biodiversity-ecosystem functioning research. Methods in Ecology and Evolution 4, 201-205. Doi:10.1111/2041-210x.12009.

Oliva, T., Desarbo, W., Day, D., Jedidi, K., 1987. GEMCAT: A general multivariate methodology for estimating catastrophe models. Behavioral Science 32, 121-137. Doi:10.1002/bs.3830320205.

Poston, T., Stewart, I., 1978. Catastrophe theory and its applications. Fearon-Pitman Publishers, Inc., Belmont, Calif. 491.

Rosser, J., 2007. The rise and fall of catastrophe theory applications in economics: was the baby thrown out with the bathwater? Journal of Economic Dynamics and Control 31, 3255-3280. Doi: 10.1037/e404992008-001.

Thom, R., Zeeman, E.C., 1975. Catastrophe theory: its present state and future perspectives. Dynamical systems: Lecture notes in mathematics 468, 366-389. Doi: $10.1007 / \mathrm{bfb0082635.}$

Wagenmakers, E.J., Molenaar, P.C.M., Grasman, R.P.P.P., Hartelman, P.A.I., Van der Maas, H.L.J., 2005. Transformation invariant stochastic catastrophe theory. Physica 211, 263-276. Doi:10.1016/j.physd.2005.08.014.

Warton, D.I., 2015. New opportunities at the interface between ecology and statistics. Methods in Ecology and Evolution 6, 363-365. Doi:10.1111/2041-210X.12345.

Warton, D.I., McGeoch, M.A., 2017. Technical advances at the interface between ecology and statistics: improving the biodiversity knowledge generation workflow. Methods in Ecology and Evolution 8, 396-397. Doi:10.1111/2041210X.12762.

Zeeman, E.C., 1976. Catastrophe theory. Scientific American 234, 65-83. Doi:10.1038/scientificamerican0476-65. 